\title{
Analisis Sistem Pengkondisian Udara Pada Ruang Kerja Kantor PT. Sarku Enjinering Utama
}

\author{
Matsuani $^{1^{*}}$ dan Suwaryo ${ }^{2}$ \\ 1). Program Studi Teknik Mesin Otomotif Institut Teknologi Indonesia \\ Jl. Raya Puspiptek Serpong, Tangerang Selatan-Banten, Indonesia, 15320 \\ 2). PT. Sarku Enjinering Utama \\ Jl. Taman Tekno IV Blok E3 No.20 Tangerang Selatan-Banten, Indonesia, 15311 \\ Email:*matsuanimatsuani@gmail.com,matsuani@iti.ac.id
}

\begin{abstract}
Air conditioning in the workspace is something that workers need to provide comfort. Generally a comfortable condition (comfort condition) is an air condition where the temperature of the dry bulb is $24^{\circ} \mathrm{C}$ to $25^{\circ} \mathrm{C}$ and wet bulb is $18.3^{\circ} \mathrm{C}$ with relative humidity of $50 \%$ to $60 \%$. The purpose of this study is to analyze the cooling requirements in the workspace which are then adjusted to the heat load in the room. In the calculation of the cooling load using the CLTD (Colling Load Temperature Difference) method. The final result is that the maximum cooling load at peak conditions is at 15:00 amounting to 14,152 $\mathrm{kW}=182,941.99 \mathrm{BTU} / \mathrm{h}$ with an air requirement of 5,756 CFM, while the installed cooling capacity is 180,000 BTU / $h$ resulting in a shortage of cooling load of 2,941, 99 BTU / h. With these deficiencies, additional air conditioning is needed as much as 2 units with each unit with a capacity of 1 PK / 9,000 BTU / h. Researchers recommend a cooling machine that is used to add capacity shortages, namely using a Split type AC cooler because it is considered more efficient and easy to install and maintain.
\end{abstract}

Keywords: Air conditioning, Ccooling capacity, CLTD

\section{PENDAHULUAN}

Udara nyaman (thermal comfort) pada suatu lingkungan sangatlah berbeda-beda, salah satu yang mempengaruhinya adalah sistem pengondisi udara yang digunakan harus sesuai dengan beban pendingin dari suatu lingkungannya. Umumnya kondisi yang nyaman (comfort condition) adalah keadaan udara dimana suhu dry bulb $24^{\circ} \mathrm{C}$ sampai $25^{\circ} \mathrm{C}$ dan wet bulb $18.3^{\circ} \mathrm{C}$ dengan kelembapan relatif (relative humidity) 50\% sampai dengan 60\% [1].

Tujuan dari penelitian ini adalah untuk menganalisis kebutuhan pendingin pada ruang kerja yang kemudian disesuaikan dengan beban kalor pada ruangan. Dalam perhitungan beban pendingin menggunakan metode CLTD (Colling Load Temperrature Difference). metode ini memiliki konsentrasi yang ketat terhadap perbedaan temperatur luar ruangan, udara lingkungan rata-rata (daily temperature), radiasi matahari dan panas dari konstruksi sebuah bangunan. Juga memiliki konsentrasi pada kondisi dari ruangannya seperti infiltrasi (air change) peralatan elektronik dan pencahayaan, yang dimana sangatlah berpengauh terhadap peningkatan beban pendinginan.

Hasil perhitungannya dapat dijadikan dasar untuk menentukan kapasitas pendingin yang dibutuhkan. Faktor pertimbangan pemilihan sistem penyegaran udara meliputi faktor kenyamanan, faktor ekonomi, serta faktor operasi dan perawatan. [2]. Persoalan yang terjadi yaitu temperatur yang bervariasi pada ruangan sehingga menjadi persoalan lingkungan kerja.

\section{Tinjauan Pustaka}

A. Definisi dan Prinsip Kerja Pengkondisi Udara

Pengkondisian udara disebut juga penyegaran udara yang memiliki arti suatu proses mendinginkan udara sehingga dapat mencapai temperatur dan kelembapan yang sesuai dengan yang dipersyaratkan terhadap kondisi udara dari suatu ruangan tertentu serta aliran udara dan kebersihannya[3]. Sistem pengkondisian udara adalah suatu proses mendinginkan udara sehingga

Copyright ${ }^{\odot} 2020$ Jurnal Rekayasa Material, Manufaktur dan Energi. This is an open acces article under the CC-BY-SA lisence (https://creativecommons.org/licenses/by-sa/4.0/). 


\section{Jurnal Rekayasa Material, Manufaktur dan Energi}

dapat mencapai temperatur dan kelembaban yang sesuai dengan yang dipersyaratkan terhadap kondisi udara suatu ruangan tertentu, mengatur aliran udara dan kebersihannya. [6]

Prinsip dasar mesin pendingin didasarkan pada kenyataan bahwa zat cair dapat diuapkan pada temperatur tertentu, dengan mengubah tekanan di atasnya. Agar suatu fluida dapat menguap maka fluida tersebut harus menyerap panas. Pada proses penyerapan panas fluida yang menguap akan mendinginkan medium dari mana panas itu diserap [4].

Refrigerasi dan pengkondisian udara (air conditioning) merupakan terapan dari teori perpindahan kalor dan termodinamika. Sifat Termodinamika merupakan karakteristik atau ciri dari ba.han yang dapat dijajaki secara kuantitatif seperti suhu, tekanan, kerapatan massa, volume spesifik, kalor spesifik, entalpi, entropi, dan sifat cair-uap dari suatu keadaan. Macam-macam sistem pengkondisian udara sebenarnya dasar thermodinamika dan komponen udara dari sistem pengkondisian udara, yaitu kompresor, kondensor, katup ekspansi, dan evaporator. Siklus pengkondisian udara ditunjukkan dalam Gambar 1.
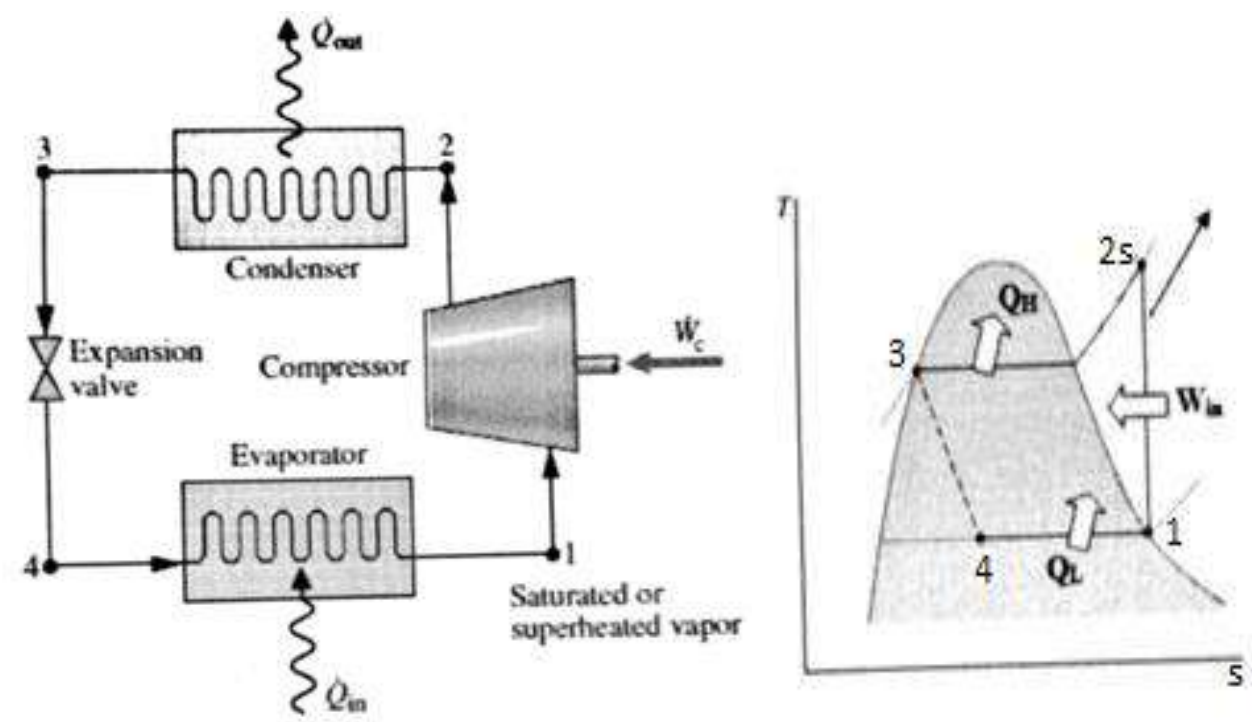

Gambar 1. Siklus Pengkondisian Udara Teoritis [4].

Keterangan gambar :

a. Proses 1-2:

Kompresi, proses yang terjadi di dalam kompresor yaitu kompresor polytrophic karena selama proses kompresi mengalirkan dan menaikkan tekanan gas refrigerant dapat berlangsung terjadi perpindahan kalor dari silinder ke sekitarnya.

b. Proses 2-3:

Kondensasi, proses pada tekanan konstan di dalam kondensor dimana terjadi perubahan fasa refrigerant dari uap menjadi cair dan terjadi penurunan enthalpy sama dengan jumlah kalor yang dilepaskan refrigerant.

c. Proses 3-4:

Ekspansi, proses terjadinya penurunan tekanan refrigerant tanpa terjadi pertukaran panas maka proses ekspansi terjadi pada enthalpy konstan

d. Proses 4-1:

Evaporasi, proses terjadi pada tekanan konstan dimana terjadi perubahan fasa refrigerant dari cair menjadi uap dan terjadi peningkatan enthalpy sama dengan jumlah kalor yang diserap refrigeran. 
Dasar Perhitungan Sistem Pendingin [5].

1. Efek Refrigerasi: Kompresi (Proses 4-1)

Efek refrigerasi adalah jumlah kalor yang diserap refrigerant selama dalam evaporator $=>R E$ $=q e=(h 1-h 4)$ Dimana:

$R E=q e=$ Efek refrigerasi $(\mathrm{kJ} / \mathrm{kg})$

$h 1=$ Enthalphi refrigeran ke luar evaporator $(\mathrm{kJ} / \mathrm{kg})$

$h 4=$ Enthalphi refrigeran evaporator $(\mathrm{kJ} / \mathrm{kg})$

$h 3=h 4$

2. Kerja Kompresi $($ proses $1-2)=>\mathrm{W}=(h 2-h 1)$

Dimana :

$\mathrm{W}=$ Kerja kompresi

$h 2=$ Entalpi keluar kondensor $(\mathrm{kJ} / \mathrm{kg})$

$h 1=$ Entalpi masuk kondensor $(\mathrm{kJ} / \mathrm{kg})$

3. Kerja Kondensor $($ proses 2-3) $\Rightarrow q c=q e+W$ atau $q c=(h 2-h 4)$

Dimana :

$q c=$ Kerja kondensor $(\mathrm{kJ} / \mathrm{kg})$

$h 2=$ Entalpi masuk kondensor $(\mathrm{kJ} / \mathrm{kg})$

$h 4=$ Entalpi refrigeran ke luar kondensor $(\mathrm{kJ} / \mathrm{kg})$

4. Jumlah Sirkulasi Refrigeran $=>M r=1 / q e$

Dimana :

$M r=$ Jumlah siklus refrigeran $(\mathrm{kg} / \mathrm{s} \mathrm{kW})$

5. Beban Pendingin yang Ditanggung Evaporator $=Q e=4,19 \times V a($ Tin - Tout $)$

Dimana :

$Q e=$ Beban pendingin $(\mathrm{kW})$

$V a=$ Volume spesifik uap refrigeran $(\mathrm{m} 3 / \mathrm{kg})$

Tin $=$ Temperatur masuk chiller $(0 C)$

Tout $=$ Temperatur ke luar chiller $(0 C)$

6. Aliran Massa Refrigerant $=>m r=Q e \times M r$

Dimana :

$m r=$ Aliran massa refrigeran $(\mathrm{kg} / \mathrm{s})$

7. Daya Motor Kompresor Teoritis $=>P t=m r(h 2-h 1)$

Dimana :

$P t=$ Daya teknis kompresi $(\mathrm{kW})$

$m r=$ Aliran massa refrigeran $(\mathrm{kg} / \mathrm{s})$

$h 1=$ Entalpi masuk kompresor $(\mathrm{kJ} / \mathrm{kg})$

$h 2=$ Entalpi ke luar kompresor $(\mathrm{kJ} / \mathrm{kg})$

8. Daya Aktual Kompresi $=>$

$$
P_{m}=\frac{P_{t}}{\pi_{t} \pi_{m}}
$$




\section{Jurnal Rekayasa Material, Manufaktur dan Energi}

Dimana :

$P m=$ Daya aktual kompresi $(\mathrm{kW})$

$P t=$ Daya teknis kompresi $(\mathrm{kW})$

$\pi t=$ Efisiensi kompresi

$\pi m=$ Efisiensi mekanis

9. Kerja sistem pendingin $=>n=P m / Q e$

Dimana :

$n=$ Kinerja sistem pendingin

$P m=$ Daya aktual kompresi $(\mathrm{kW})$

$Q e=$ Beban pendingin $(\mathrm{kW})$

10. Perbandingan kompresi $=>r=P 2 / P 1$

Dimana :

$\mathrm{r}=$ Perbandingan kompresi

$P 2=$ Tekanan ke luar kompresor $(\mathrm{kPa})$

$P 1=$ Tekanan ke luar evaporator $(\mathrm{kPa})$

11. COP ( Coefficient Of Performance $) \Rightarrow C O P=(h 1-h 4) /(h 2-b A)$

Dimana :

COP $=$ Coefficient of Performance

$h 1=$ Enthalpy masuk kompresor $(\mathrm{kJ} / \mathrm{kg})$

$h 2=$ Enthalpy masuk kondensor $(\mathrm{kJ} / \mathrm{kg})$

$h 4=$ Entalpi masuk evapporator $(\mathrm{kJ} / \mathrm{kg})$

12. Kapasitas $=>V=M r \times V a$

Dimana :

$V=$ Kapasitas $(\mathrm{m} 3 / \mathrm{Jam})$

$M r=$ jumlah siklus refrigeran $(\mathrm{kg} / \mathrm{s} * \mathrm{~kW})$

$V a=$ Volume spesifik uap refrigeran $(\mathrm{m} 3 / \mathrm{kg})$

B. Pengumpulan Data

Pengumpulan data diperlukan untuk perhitungan dan analisa. Adapun data awal perhitungan yang diambil adalah sebagai berikut:

Tabel 1. Data Awal Perhitungan

\begin{tabular}{llc}
\hline No & \multicolumn{1}{c}{ Deskripsi } & Jumlah \\
\hline 1 & Data Ruang & \\
& Luas Lantai & $450 \mathrm{~m}^{2}$ \\
& Luas Atap & $450 \mathrm{~m}^{2}$ \\
& Tinggi Bangunan & $5 \mathrm{~m}^{2}$ \\
& Luas Dinding: & \\
Timur & $30 \mathrm{~m}^{2}$ \\
Barat & $35 \mathrm{~m}^{2}$ \\
Selatan & $10 \mathrm{~m}^{2}$ \\
& Utara & $15 \mathrm{~m}^{2}$ \\
\hline
\end{tabular}

Copyright $^{\circledR} 2020$ Jurnal Rekayasa Material, Manufaktur dan Energi. This is an open acces article under the CC-BY-SA lisence (https://creativecommons.org/licenses/by-sa/4.0/). 


\begin{tabular}{llc}
\hline No & \multicolumn{1}{c}{ Deskripsi } & Jumlah \\
\hline 2 & Data Lampu : & \\
& Lampu Neon (30 Watt) & 20 Lampu \\
3 & Data Jumlah Pekerja: & \\
& Pria & 20 orang \\
& Wanita & 5 orang \\
4 & Data Pintu dan Jendela: & \\
& Pintu & 1 buah \\
& Jendela & 12 buah \\
5 & Data Peralatan: & \\
& PC (450 Watt) & 25 buah \\
& Mesin Foto Copy (1500Watt) & 1 buah \\
& Proyektor (225 Watt) & 2 buah \\
& Printer (650 Watt) & 5 buah \\
& & \\
Data mesin pendingin yang terpasang & Panasonic CS-YN18TKP AC Split \\
& Merek & 2 PK \\
& Kapasitas & R-32 \\
Type Refrigrant & 1660 Watt \\
Daya Listrik & 18000 BTU/h \\
Kapasitas Pendingin & 10 Unit \\
Jumlah yang terpasang & 180.000 BTU/h \\
Total Kapasitas pendingin & \\
\hline
\end{tabular}

C. Perhitungan Beban Kalor Pendingin (CLTD) [1].

1. Beban kalor melalui dinding dan atap

Untuk Dinding :

$\mathrm{q}_{\mathrm{TD}}=\mathrm{U}_{\mathrm{TD}} \times \mathrm{A}_{\mathrm{TD}} \times \Delta \mathrm{T}$

Untuk Atap :

$\mathrm{q}_{\mathrm{TA}}=\mathrm{U}_{\mathrm{TA}} \times \mathrm{A}_{\mathrm{TA}} \times \Delta \mathrm{T}$

Keterangan :

$\mathrm{q}_{\mathrm{TD}}=$ Beban kalor dinding (Watt)

$\mathrm{q}_{\mathrm{TA}}=$ Beban kalor atap (Watt)

$\mathrm{U}_{\mathrm{TD}}=$ Koefisien kalor untuk dinding $\left(\mathrm{W} / \mathrm{m}^{2} \mathrm{~K}\right)$

$\mathrm{U}_{\mathrm{TA}}=$ Koefisien kalor untuk atap $\left(\mathrm{W} / \mathrm{m}^{2} \mathrm{~K}\right)$

$\mathrm{A}_{\mathrm{TD}}=$ Luas dinding $\left(\mathrm{m}^{2}\right)$

$\mathrm{A}_{\mathrm{TA}}=$ Luas atap $\left(\mathrm{m}^{2}\right)$

$\Delta \mathrm{T}=\mathrm{Te}-\mathrm{TI}$

$\mathrm{Te}=$ Temperatur ekuivalen $\left({ }^{\circ} \mathrm{C}\right)$

$\mathrm{TI}=$ Temperatur yang dikondisikan $\left({ }^{\circ} \mathrm{C}\right)$

2. Beban kalor oleh penerangan

Beban kalor yang dilepaskan oleh lampu penerangan dapat dihitung dengan pendekatan sebagai berikut:

$\mathrm{q}_{\mathrm{L}}=1,2 \times \mathrm{D} \times \mathrm{CLF}$ 


\section{Jurnal Rekayasa Material, Manufaktur dan Energi}

Keterangan :

$\mathrm{q}_{\mathrm{L}} \quad=$ Beban kalor oleh penerangan (Watt)

$\mathrm{D}=$ Daya lampu total

$\mathrm{CLF}=$ Faktor beban pendingin dari penerangan

3. Beban kalor pekerja

Kalor yang dikeluarkan oleh pekerja terdiri dari kalor sensibel dan kalor laten hubungan untuk memperhitungkan beban kalor pekerja adalah:

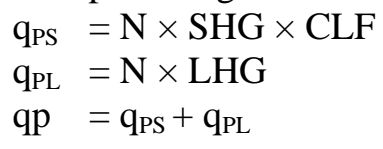

Keterangan :

$\begin{array}{ll}\mathrm{q}_{\mathrm{PS}} & =\text { Beban kalor sensibel pekerja }(\mathrm{kW}) \\ \mathrm{q}_{\mathrm{PL}} & =\text { Beban kalor laten pekerja }(\mathrm{kW}) \\ \mathrm{qp} & =\text { Beban kalor pekerja }(\mathrm{kW}) \\ \mathrm{N} & =\text { Jumlah pekerja dalam ruangan } \\ \mathrm{SHG} & =\text { Kalor sensibel yang dilepaskan pekerja } \\ \mathrm{CLF} & =\text { Jumlah kelompok orang yang bekerja } \\ \mathrm{LHG} & =\text { Kalor laten yang dilepaskan pekerja }\end{array}$

4. Beban kalor sensibel peralatan

Kalor yang dilepaskan oleh peralatan mesin yang ada di ruangan dapat dihitung dengan :

$\mathrm{q}_{\mathrm{E}} \quad=\mathrm{N} \times \mathrm{U}_{\mathrm{E}}$

Keterangan :

$\mathrm{q}_{\mathrm{E}} \quad=$ Beban kalor sensibel peralatan $(\mathrm{kW})$

$\mathrm{N} \quad=$ Jumlah peralatan $(\mathrm{kW})$

$\mathrm{U}_{\mathrm{E}} \quad=$ Faktor koefisien peralatan $(\mathrm{Kcal} / \mathrm{kWh})$

5. Beban kalor sensibel pintu dan jendela

Kalor sensibel pintu dan jendela tergantung dari bahan dan luasan perbendaan temperatur dalam dan luar:

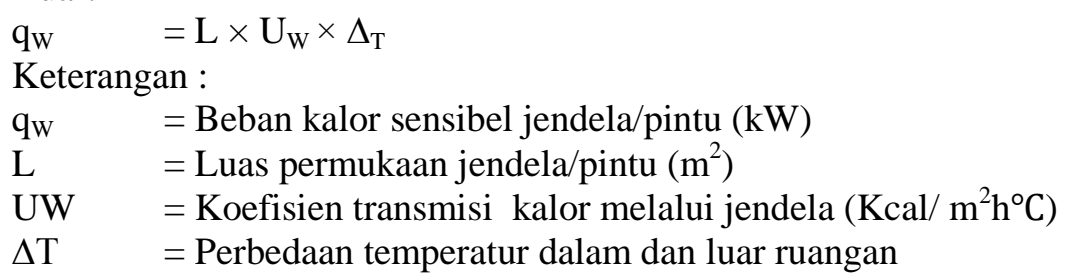

6. Beban kalor total

Beban kalor total merupakan kalor terbesar yang harus terjadi dan yang harus dilayani oleh mesin pendingin. Beban kalor yang terjadi dapat diperoleh dari persamaan berikut:

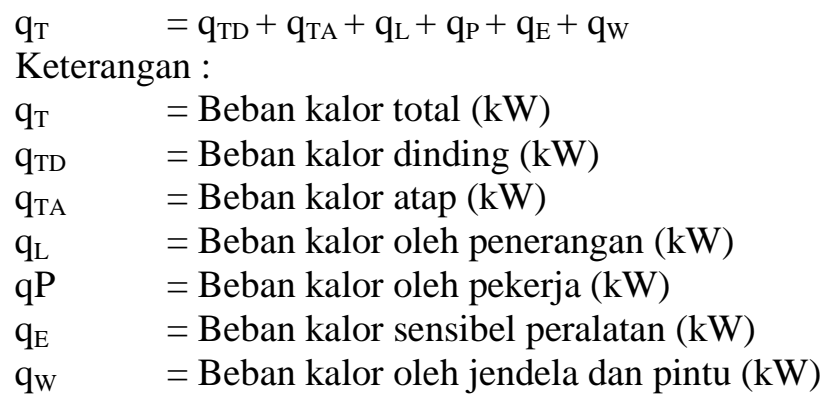




\section{METODE PENELITIAN}

Hal pertama yang harus dilakukan adalah pengambilan data di ruang kerja PT. Sarku Enjinering Utama, peneliti akan melakukan penelitian secara langsung pada sampel objek yang yang akan dirancang dengan mengumpulkan data-data seperti luas ruangan, volume ruangan, posisi ruangan dan lain-lain. Yang kemudian akan dibandingkan dengan hasil perancangan yang berdasarkan metodologi dan tahapan-tahapan perancangan yang dilakukan. Adapun metodologi yang dilakukan oleh peneliti untuk mengumpulkan data-data adalah sebagai berikut:

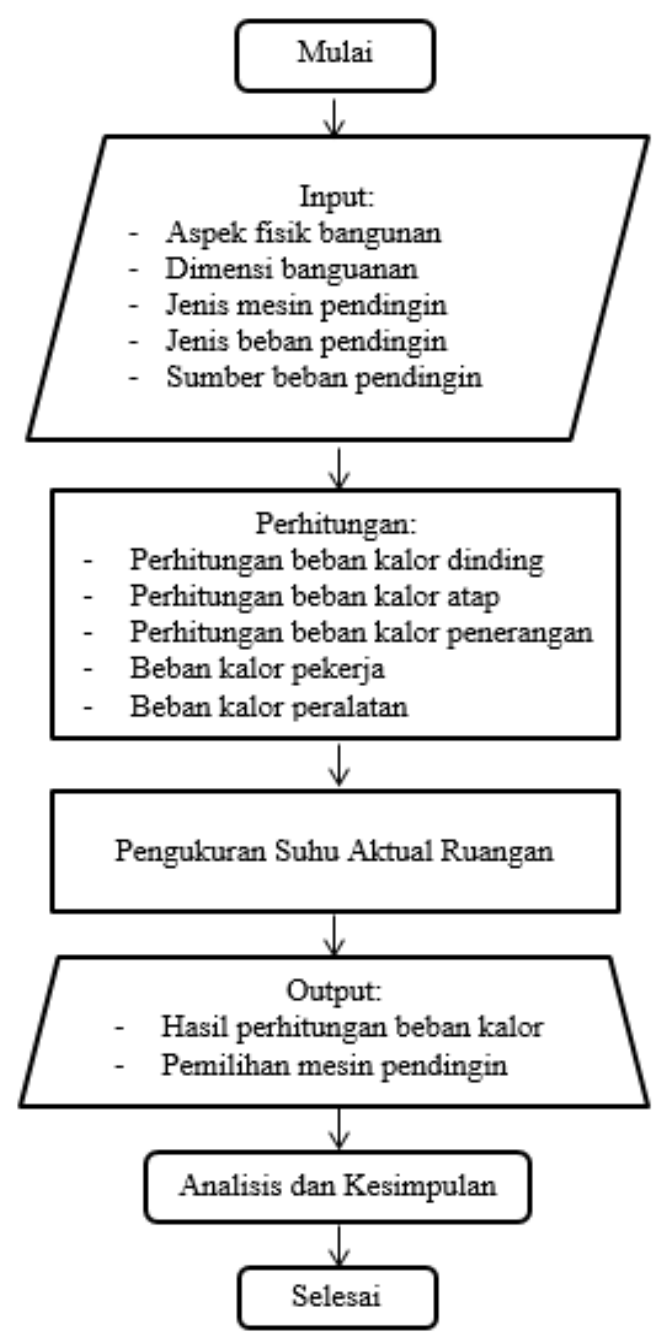

Gambar 2. Diagram Alir Perencanaan

\section{HASIL DAN PEMBAHASAN}

Dasar yang digunakan adalah perhitungan CLTD menurut Arismunandar, 1981. Perhitungan dilakukan selama jam kerja di ruang kerja di PT. Sarku Enjinering, dengan mengambil data kondisi pada pukul 12:00.

(1) Temperatur udara luar sesaat $=31,46^{\circ} \mathrm{C}$

(2) Ketinggian matahari $=74^{\circ} \mathrm{C}$ (pukul 12:00)

(3) Azimut matahari $=180^{\circ}$

(4) Radiasi matahari langsung $=239 \mathrm{w} / \mathrm{M}^{2}$

(5) Radiasi matahari langsung pada bidang yang tegak lurus arah datangnya radiasi $=286 \mathrm{~W} / \mathrm{M}$

Copyright ${ }^{\odot} 2020$ Jurnal Rekayasa Material, Manufaktur dan Energi. This is an open acces article under the CC-BY-SA lisence (https://creativecommons.org/licenses/by-sa/4.0/). 


\section{Jurnal Rekayasa Material, Manufaktur dan Energi}

(6) Sudut sinar datang pada permukaan yang tegak lurus bidang horizontal dinding dengan sudut $\Sigma=90^{\circ}=106^{\circ}$ pada arah selatan

(7) Radiasi matahari langsung terhadap bidang horizontal $=175^{\mathrm{W}} / \mathrm{M}^{2}$

(8) Radiasi terpancar difusi $=69 \mathrm{w} / \mathrm{M}^{2}$

(9) Intesitas matahari total $=308 \mathrm{w} / \mathrm{M}^{2}$

(10) Radiasi udara matahari $=32^{\circ}$

(11) Beban kalor pada dinding $=0,428 \mathrm{~kW}$

(12) Beban kalor atap $=6,051 \mathrm{~kW}$

(13) Beban kalor oleh penerangan $=0,633 \mathrm{~kW}$

(14) Beban kalor pekerja $=25,684 \mathrm{~kW}$

(15) Beban kalor sensible peralatan $=14,152 \mathrm{kcal} / \mathrm{jam}$

(16) Beban kalor total pukul 12:00 $=46,948 \mathrm{~kW}$

Berikut adalah tabel hasil perhitungan beban kalor total setiap jamnya:

Tabel 2 Beban Kalor Total

\begin{tabular}{ccccccc}
\hline $\mathbf{J a m}$ & $\mathbf{q}_{\mathbf{T D}}(\mathbf{k W})$ & $\mathbf{q}_{\mathbf{T A}}(\mathbf{k W})$ & $\mathbf{q}_{\mathbf{L}}(\mathbf{k W})$ & $\mathbf{q}_{\mathbf{P}}(\mathbf{k W})$ & $\mathbf{q}_{\mathbf{E}}(\mathbf{k W})$ & $\mathbf{q}_{\mathbf{T}}(\mathbf{k W})$ \\
\hline 8 & 0,153 & 0,865 & 0,072 & 24,994 & 14,152 & 40,236 \\
9 & 0,22 & 2,248 & 0,5472 & 25,270 & 14,152 & 42,437 \\
10 & 0,315 & 3,458 & 0,5832 & 25,436 & 14,152 & 43,9442 \\
11 & 0,371 & 4,841 & 0,6048 & 25,574 & 14,152 & 45,5428 \\
12 & 0,428 & 6,051 & 0,633 & 25,684 & 14,152 & 46,948 \\
13 & 0,479 & 6,916 & 0,648 & 25,795 & 14,152 & 47,99 \\
14 & 0,535 & 7,434 & 0,6624 & 25,850 & 14,152 & 48,6334 \\
15 & 0,58 & 7,434 & 0,6696 & 25,905 & 14,152 & 48,7406 \\
16 & 0,535 & 7,089 & 0,6840 & 24,635 & 14,152 & 47,095 \\
\hline
\end{tabular}

Dari Tabel 2 dapat dilihat bahwa beban kalor terbesar terjadi pada pukul 15:00 yaitu sebesar 48,7406 $\mathrm{kW}$. Akan tetapi masih ada berbagai faktor yang belum kita ketahui misalnya service load yaitu panas lain yang timbul dalam proses operasi pendinginan seperti kipas, operator, udara luar ketika pintu dibuka. Maka dari itu beban kalor ditambah $10 \%$ dari beban kalor total yang diperoleh sebagai faktor keamanan, sehingga beban kalor menjadi 53,615 kW. Dari hasil perhitungan beban kalor total di atas dapat dibuat grafik beban kalor total pada Gambar 3 berikut ini:

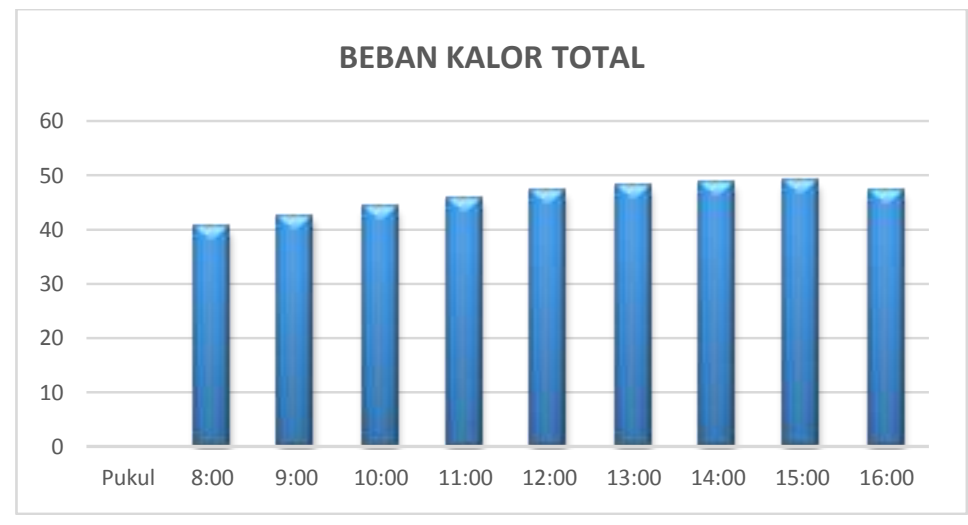

Gambar 3. Grafik Beban Kalor Total

Copyright $^{\circledR} 2020$ Jurnal Rekayasa Material, Manufaktur dan Energi. This is an open acces article under the CC-BY-SA lisence (https://creativecommons.org/licenses/by-sa/4.0/). 
Perhitungan Kebutuhan Laju Udara (CFM)

Perhitungan untuk menentukan besaran volume udara suplai yaitu:

$\mathrm{Q}=(\mathrm{V} \times \mathrm{ACH}) / 1,7$

Keterangan :

$\mathrm{Q} \quad=$ Volume udara $(\mathrm{CFM})$

$\mathrm{V} \quad=$ Volume ruangan $\left(\mathrm{m}^{3}\right)$

$\mathrm{ACH}=$ Pertukaran udara perjam

Berikut adalah tabel perhitungan kebutuhan laju udara pada ruang kerja:

Tabel 3 Kebutuhan Laju Udara

\begin{tabular}{cccccccc}
\hline No & Nama Ruangan & \multicolumn{3}{c}{ Volume $\left(\mathbf{m}^{3}\right)$} & ACH & Q & Safety Factor \\
\cline { 2 - 6 } & & $\mathbf{p}$ & $\mathbf{l}$ & $\mathbf{t}$ & & & \\
\hline $\mathbf{1}$ & 1 & 9 & 7,5 & 3 & 15 & 1.191 & 5.756 \\
$\mathbf{2}$ & 4 & 15 & 7 & 3 & 15 & 2.779 & 5.756 \\
$\mathbf{3}$ & 6 & 7,5 & 6 & 3 & 15 & 1.786 & 5.756 \\
\hline
\end{tabular}

Pada Tabel di atas diketahui kebutuhan laju udara (CFM) dibagi menjadi tiga titik perhitungan yaitu pada ruang 1, ruang 4, dan ruang 6 sehingga total hasil laju aliran sebesar 5.756 CFM.

\section{KESIMPULAN}

Dari hasil pengamatan, kapasitas total unit mesin pendingin yang dipakai di ruang kantor PT. Sarku Enjinering Utama sebanyak 10 unit AC Split dengan kapasitas 2 PK/unit adalah 180.000 BTU. Beban kalor total tertinggi pada perhitungan secara teoritis yaitu pukul 15:00, dimana kondisi maksimum yang dibutuhkan yaitu 53,615 kW $=182.941,99$ BTU. Beban kalor oleh peralatan sebesar 14,152 kW dan Kebutuhan laju udara (CFM) dibagi menjadi tiga titik perhitungan yaitu pada ruang 1, ruang 4, dan ruang 6 yang mendapatkan hasil laju aliran sebesar 5.756 CFM. Setelah dilakukan analisis dan perhitungan dapat disimpulkan bahwa mesin yang sudah terpasang memiliki kapasitas sebesar $20 \mathrm{PK}$ atau 180.000 BTU sedangkan beban kalor yang telah dihitung sebesar 182.941,99 BTU.

\section{SARAN}

Dengan kondisi mesin yang sudah terpasang memiliki kapasitas sebesar 20 PK atau 180.000 BTU sedangkan beban kalor yang telah dihitung sebesar 182.941,99 BTU maka AC yang telah terpasang belum dapat memenuhi kebutuhan beban kalor sesuai yang diperhitungkan. Kekurangan tersebut yaitu sebesar 2.941,99 BTU dan perlu adanya penambahan 2 unit AC kapasitas 1 PK/unit agar dapat memenuhi kebutuhan kalor.

\section{UCAPAN TERIMA KASIH}

Penelitian ini dapat diselesaikan dengan bantuan dan bimbingan dari berbagai pihak. Oleh karena itu ucapan terima kasih sebesar-besarnya disampaikan kepada PT. Sarku Enjinering Utama yang telah banyak membantu dalam usaha memperoleh data yang diperlukan dan terimakasih kepada seluruh pihak telah terlibat dalam penelitian ini yang tidak dapat penulis tuliskan satu persatu.. 


\section{REFERENSI}

[1] Wiranto Arismunandar, Buku Penyegaran udara, Koleksi Buku Perpustakaan Digital ITB, 1991

[2] ASHRAE, Handbook of Air Conditioning Fundamental, ASHRAE, 2001.

[3] V. V. Prathibha Bharathi, Ajay Kodliwad, Busi Ashok Kumar, V. V. Naga Deepthi. Design of Conditioning System for Residential/Office Building. 2017 [3].

[4] Felix Uba,.Fiagbe Yesuenyeagbe., Sarsah Emmanuel. Simplified Procedure For Estimating Air-Conditioning Cooling Load In Ghana. 2015 [4].

[5] Yonas Mitiku Degu. Cooling Load Estimation and Air Conditioning Unit Selection for Hibir Boat. The International Journal Of Engineering And Science (IJES). 2016

[6] Sabaruddin, Perhitungan Ulang Beban Pendinginan Pada Ruang Auditorium Gedung Manggala Wanabakti Blok III Kementerian Kehutanan Jakarta. Mercu Buana Jakarta. Sinergi. 2014 